\title{
Evaluation of Recent Upgrades to the NESS (Nuclear Engine System Simulation) Code
}

\author{
James E. Fittje* \\ Analex Corp. at NASA Glenn Research Center, Brook Park, OH 44135 \\ Bruce G. Schnitzler ${ }^{\dagger}$ \\ NASA Glenn Research Center, Brook Park, OH, 44135 \\ Intergovernmental Personnel Act (IPA) Assignee from Idaho National Laboratory
}

\begin{abstract}
The Nuclear Thermal Rocket (NTR) concept is being evaluated as a potential propulsion technology for exploratory expeditions to the moon, Mars, and beyond. The need for exceptional propulsion system performance in these missions has been documented in numerous studies, and was the primary focus of a considerable effort undertaken during the Rover/NERVA program from 1955 to 1973. The NASA Glenn Research Center is leveraging this past NTR investment in their vehicle concepts and mission analysis studies with the aid of the Nuclear Engine System Simulation (NESS) code. This paper presents the additional capabilities and upgrades made to this code in order to perform higher fidelity NTR propulsion system analysis and design, and a comparison of its results to the Small Nuclear Rocket Engine (SNRE) design.
\end{abstract}

\section{Nomenclature}

GRC $=$ Glenn Research Center (NASA)

CERMET $=$ Advanced Ceramic/Metallic Fuel

MCNP $=$ Monte Carlo N-Particle transport code

NESS $=$ Nuclear Engine System Simulation

NERVA $=$ Nuclear Engine for Rocket Vehicle Applications

NTR $=$ Nuclear Thermal Rocket

Isp $\quad=$ Specific Impulse

SNRE $\quad=$ Small Nuclear Rocket Engine

$\mathrm{TPA} \quad=$ Turbopump Assembly

\section{Introduction}

Sacecraft propulsion technology impacts practically every aspect of vehicle performance and mission design. Nuclear Thermal Rocket (NTR) technology can deliver specific impulse (Isp) values more than double that of any chemical based system by heating low molecular weight hydrogen propellant to over $2600 \mathrm{~K}$ via thermal energy gained from a nuclear fission reactor ${ }^{1}$.

The requirement for exceptional propulsion system performance has been documented in numerous studies, and was the primary focus of the work done during the Nuclear Engine for Rocket Vehicle Applications (NERVA) program $^{2}$. The NASA Glenn Research Center (GRC) is leveraging this investment by creating and analyzing vehicle concepts based on NTR technology with the aid of the Nuclear Engine System Simulation (NESS) code. The primary focus of recent activities ${ }^{3,4}$ at NASA GRC has been on benchmarking and upgrading methods, models, and analysis tools against the Small Nuclear Rocket Engine (SNRE) design ${ }^{5}$. Although never built, the SNRE has been the primary benchmark focus, primarily because of the maturity of the design and the available documentation regarding its preliminary design results.

\footnotetext{
* Aerospace Engineer, 21000 Brookpark Road , MS: GES-AOS, AIAA Senior Member

${ }^{\dagger}$ INL Staff Member, Space Nuclear Systems Division, 21000 Brookpark Road, MS 77-5, AIAA Senior Member
} 


\section{Nuclear Thermal Rocket (NTR) System Overview}

A basic NERVA derived NTR propulsion system, as shown in Fig. 1, consists of a small nuclear fission reactor, turbopump assembly (TPA), nozzle, radiation shield, pressure vessel, and the associated lines and support hardware. These systems are typically expander cycle based, and thus utilize thermal energy gained by the propellant, typically hydrogen, from active cooling of various engine subcomponents (nozzle, control drums, etc.) to drive the TPA, and thus power the cycle ${ }^{1}$. As designs evolved during the early years of nuclear rockets, chamber pressure and engine size increased, thus additional energy was required to meet the increasing power requirements of the TPA. In response to this requirement, later designs began to extract additional thermal energy directly from the reactor core by utilizing the actively cooled tie tube structural elements. This design's heritage dates back to the NERVA program ${ }^{2}$, and is represented in $\mathrm{NESS}^{6}$. A simplified flow diagram of a typical expander cycle based NTR engine is shown in Fig. 2.

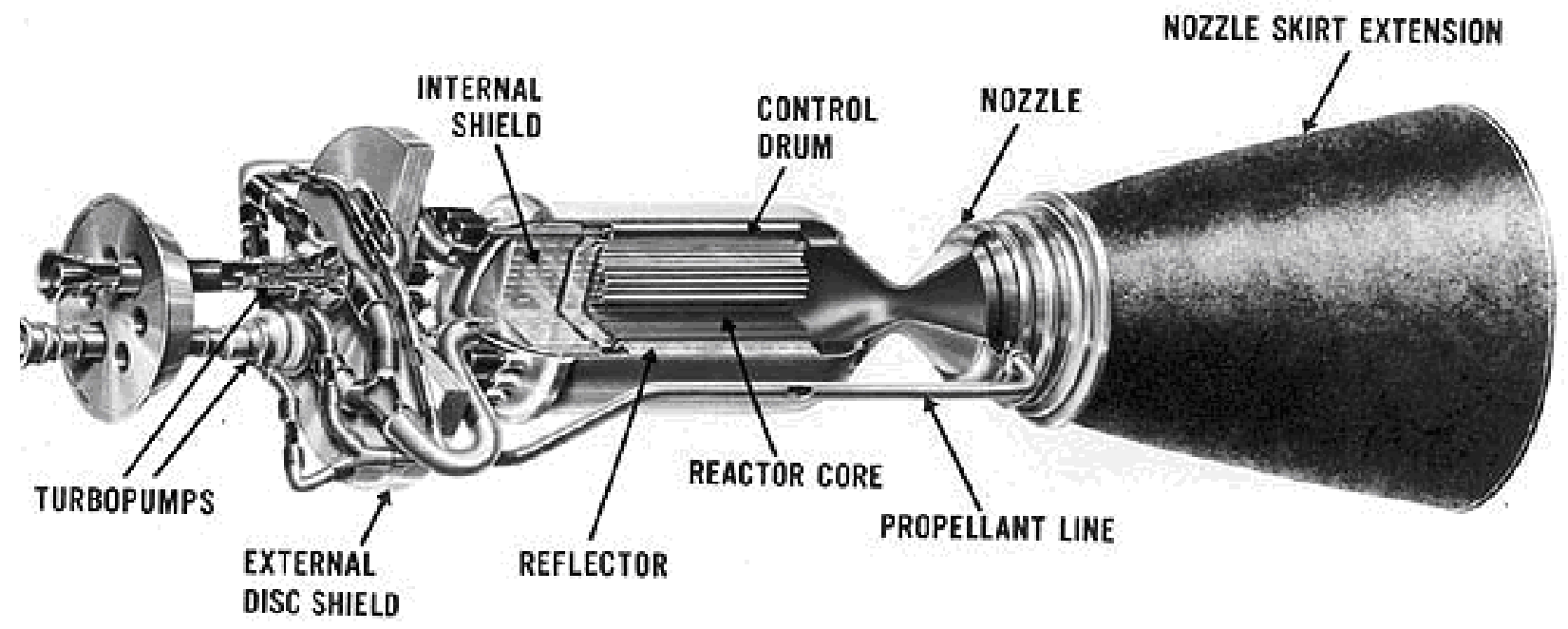

Figure 1. Typical NERVA Derived NTR Engine System.

\section{A. Reactor Assembly}

In a NERVA derived NTR system, tie tubes and fuel elements are assembled to create the reactor core. In this assembly, the ratio of fuel elements to tie tubes is adjustable. A typical arrangement is shown in Fig. 3, where each tie tube is surrounded by six fuel elements, and each fuel element is in contact with three tie tubes. The fuel elements around the perimeter of the core, however may contact fewer tie tubes ${ }^{2}$.

The assembled reactor core is surrounded by additional and partial hexagonal beryllium or graphite filler elements, which are used to complete a cylindrical core. The core assembly is then surrounded by a beryllium reflector containing the control drums. The control drums consist of a neutron moderator-reflector on one side and a neutron absorber on the other, and are the same length as the tie tubes and the fuel elements. Thus, the reactor reactivity can be adjusted by rotating the control drums. This entire assembly is then placed inside a pressure vessel $^{1,7}$. A cross section view of a typical NERVA derived reactor assembly is shown in Fig. 3.

\section{B. Tie Tubes and Fuel Elements}

A tie tube is a hexagonal shaped axial support element which also serves as a dual pass heat exchanger through the length of the reactor. Cold working fluid, typically the hydrogen propellant, is first sent down the center of the tie tube, and then returns via an outer coaxial annular flow path while extracting thermal energy from the reactor core, which is later used to drive the TPA. Tie tubes are the same size (typically $1.905 \mathrm{~cm}$ across the flats) as a reactor fuel element. NERVA derived uranium and graphite based fuel elements are also hexagonal in cross-section, and typically incorporate 19 equally spaced holes that are $\sim 2.54 \mathrm{~mm}$ in diameter. These 19 holes are the flow path for the propellant to pass through the reactor and into the thrust chamber located at the bottom of the reactor ${ }^{1,5}$. Typical NERVA derived tie tube and fuel element cross sections are shown in Fig. 4. 


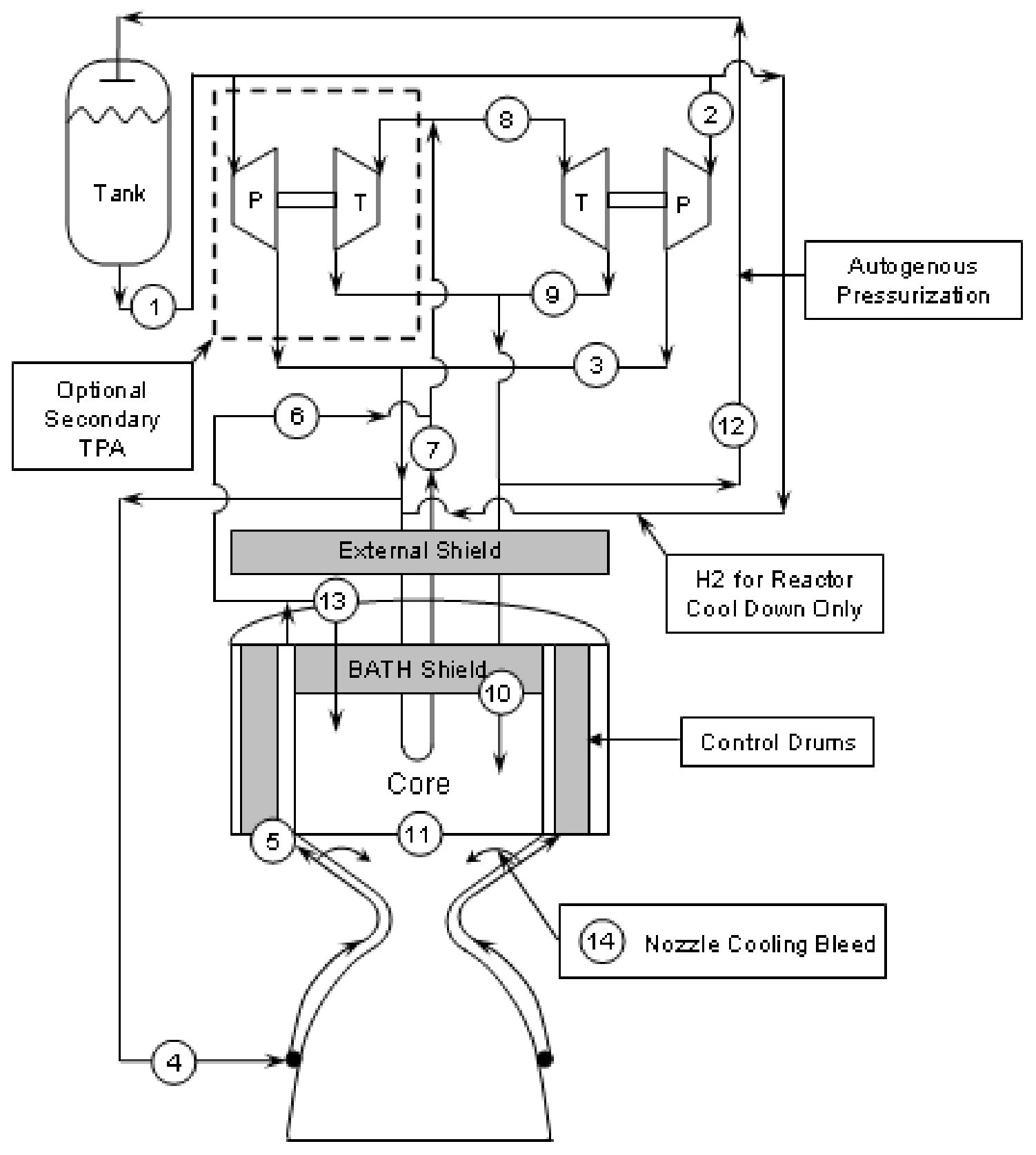

Figure 2. Typical Expander Cycle NTR Flow Diagram.

\section{NTR Fuels}

There are several NTR fuel candidates available that cover a wide range of operational temperatures. These fuels range from the well understood coated $\mathrm{UC}_{2}$ in graphite to the more exotic tricarbide ${ }^{8,9,10}$. The NESS default fuel is (U,Zr)C-Graphite composite ${ }^{9}$, which was tested during the NERVA program in the Nuclear Furnace 1 test reactor ${ }^{10}$. Due to this testing, and its higher operational temperature relative to the coated $\mathrm{UC}_{2}$ in graphite, it is the most likely fuel candidate in the near term. NESS, however, can easily accept new fuel types, such as the ceramic and metal matrix (CERMENT) class of fuels as they become available ${ }^{1}$. 


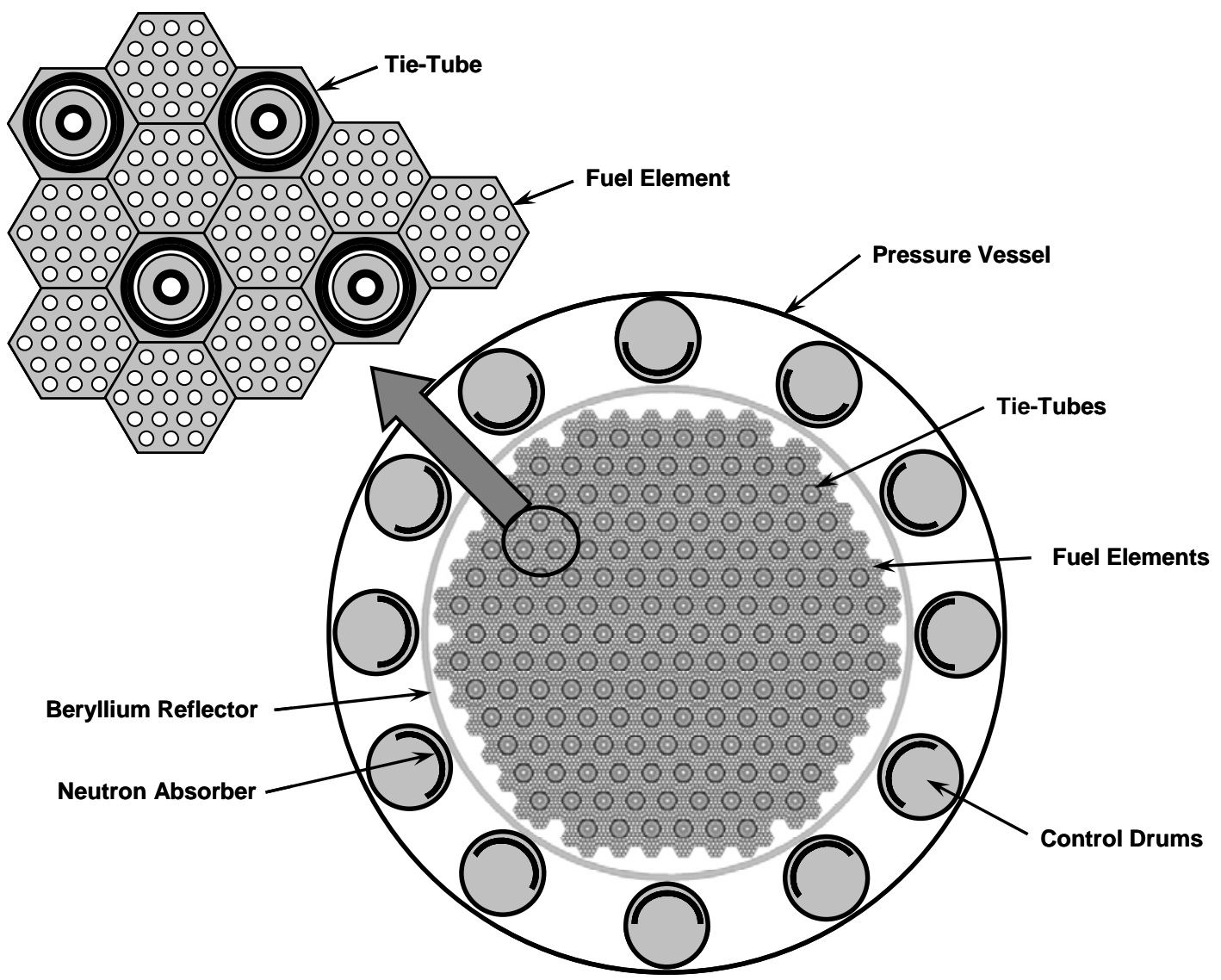

Figure 3. Typical NERVA Derived Reactor Cross Section.

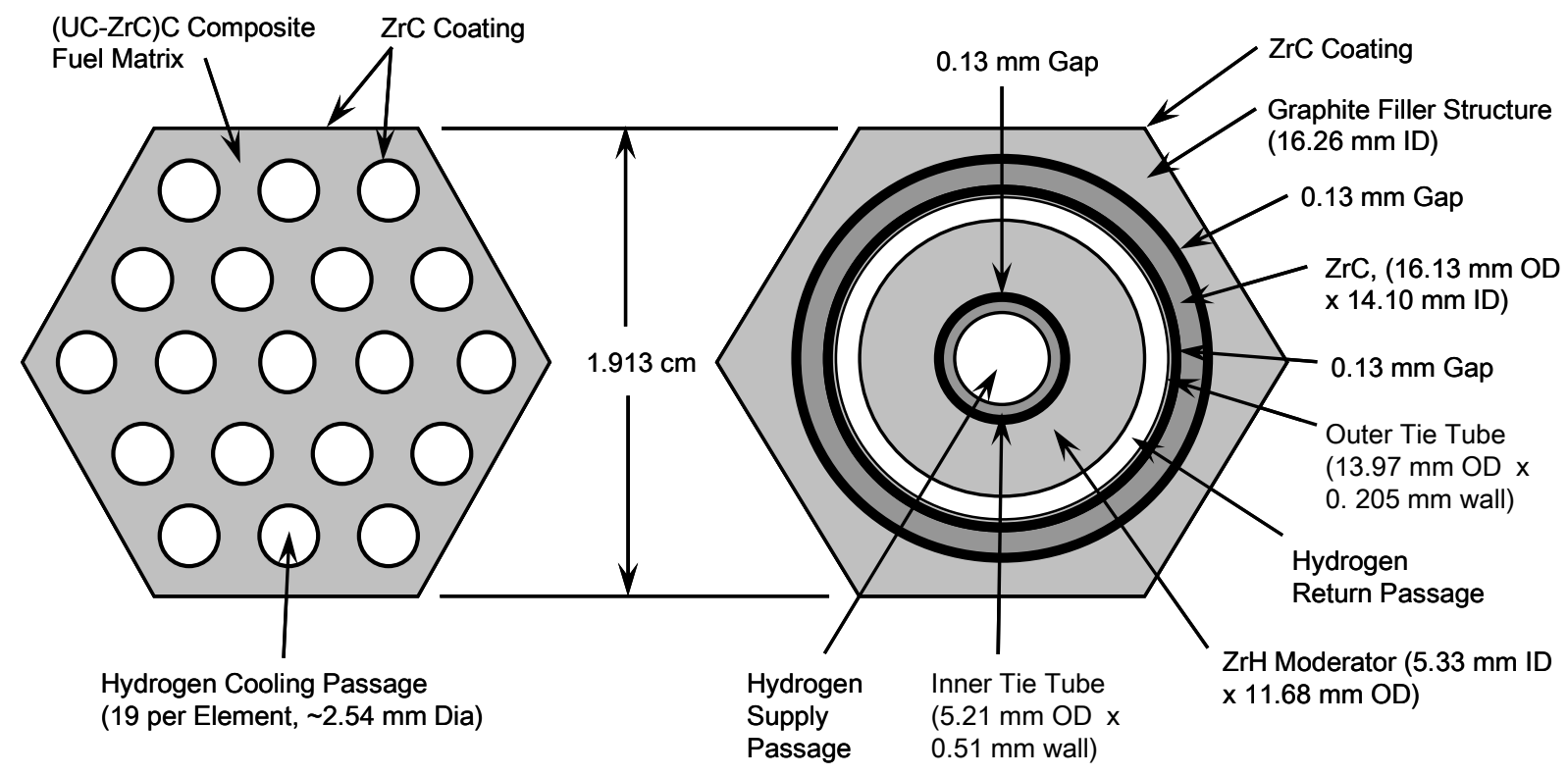

a) Typical NERVA Derived Fuel Element

b) Typical NERVA Derived Tie Tube

Figure 4. Tie Tube and Fuel Element Cross Sections. Tie-Tube gaps represent cold (not operating) conditions. 


\section{NESS Program}

The NESS program ${ }^{6}$ was developed for rapid preliminary design and analysis of NERVA derived NTR propulsion systems. It is derived from the Expanded Liquid Engine Simulation program, which was modified to include Westinghouse Electric Corporation's near-term solid-core reactor design models Enabler-I and Enabler-II. NESS can perform preliminary design of NERVA derived NTR propulsion systems, and estimate the weight, performance, size, and operating characteristics of NTR propulsion system components. Code outputs also include engine cycle parameters including pressures, temperatures, and mass flows. NESS can model expander, gas generator, and bleed cycles. All of these engine cycles can be driven by either a single or dual TPA configuration, with the TPA being either a common shaft or geared type ${ }^{1,6}$.

Recently, several NESS algorithms have been upgraded. These include the conversion of the liquid hydrogen properties package to GASPLUS ${ }^{11}$, expanded heat transfer and energy balance logic ${ }^{12}$, improved design and performance calculations, and the ability to accept reactor inputs from the MCNP code in several formats. Although NESS can still be used in a design mode with all of its original features, the recent upgrades allow it to operate in an analysis mode by directly incorporating nuetronics and energy and thermal energy deposition results from a Monte Carlo N-Particle (MCNP) ${ }^{13}$ analysis.

\section{SNRE Model}

\section{A. SNRE Background}

The NTR system selected for benchmarking the upgraded NESS code is the Small Nuclear Rocket Engine (SNRE). This engine was well documented in the Nuclear Engine Definition Study ${ }^{5,14}$ which was performed at Los Alamos Scientific Laboratory in 1972 just before the Rover/NERVA program was cancelled, and incorporates lessons learned from the design and testing of previous NTR systems. The SNRE was designed to utilize 564 (U, $\mathrm{Zr}$ )C-graphite composite fuel elements and 241 tie tubes, all of which were $0.89 \mathrm{~m}$ in length. This arrangement would yield approximately 367 MW of thermal power and yield a specific impulse of $875 \mathrm{~s}$ via a 100:1 area ratio nozzle that is regeneratively cooled to an area ratio of 25:1.

\section{B. MCNP Model}

Analysis of nuclear engines using the combination of MCNP and NESS requires both consideration of the reactor core models to be employed for the MCNP Monte Carlo transport calculation and selection of specific output options from that calculation for subsequent use in NESS. The SNRE core was modeled at six different levels of detail, with three of the models being particularly well suited for use in conjunction with NESS.

The composite fuel elements, shown in Fig. 4, are modeled with an active fuel length of $89 \mathrm{~cm}$ (35 in), 19 propellant coolant channels with a $0.25654-\mathrm{cm}(0.101$-in) borehole diameter, a borehole pitch of $0.40894 \mathrm{~cm}(0.161$ in), and a 50 micrometer thick $\mathrm{ZrC}$ outer surface coating. The fuel matrix, propellant channels, and $\mathrm{ZrC}$ coatings on the fuel channels and outer hexagonal surfaces are all explicitly modeled. The actual interior borehole coating thickness increases gradually from about 50 micrometer at the inlet to about 150 micrometer at the outlet end. A uniform 100 micrometer thickness is assumed for the MCNP models.

Tie tube elements, also shown in Fig. 4, contain 11 explicitly modeled 89-cm long components. Most of the hot end support assembly model is included as a lower extension of the tie tube model. As a modeling convenience, the support arches below each fuel element are incorporated into a lower extension of the fuel element model.

The Explicit Lattice model is the most highly detailed and serves as the computational benchmark. The model consists of a single tie tube element and a single fuel element as described above, and a beryllium filler element. These three hexagonal element models all have identical exterior dimensions. The $\mathrm{MCNP}^{13}$ lattice feature is used to propagate the three element types and completely fill the reactor core region. The Explicit Lattice type model is referenced as "explicit" later in the text.

The Homogenized Lattice model is similar, except the fuel element and tie tube element models both consist of a single homogenized zone. The zone material composition is established by volume weighting the material compositions of the element components. The MCNP lattice feature is again used to propagate the three element types and completely fill the reactor core region. Models of this type typically provide faster running times but sacrifice interior detail such as tie tube component heating rates.

The Homogenized Discrete model consists of 564 fuel elements, 241 tie tube elements, and 120 complete or partial beryllium filler elements. Homogenized material compositions, identical for each element type, are employed, but each element is individually constructed using six exterior surfaces making up the faces of the hexagonal element plus the aft and forward surfaces. Given the same homogenized compositions for each of the 
element types, results from the Homogenized Lattice and Homogenized Discrete models should be identical within Monte Carlo statistical errors. Both the Homogenized Lattice and Homogenized Discrete models are referenced as "homogenized" later in the text.

Calculated energy deposition rates and their associated spatial distributions are the primary data exported to NESS. For homogenized element models, total energy deposition rates (sum of neutron and gamma deposition) are summed over the 89-cm length of the element and output separately for each fuel and tie tube element. For explicit element models, however, the total energy deposition rate is output for each of the individual components of each respective element. Energy deposition rate data are also available for a user-specified number of axial segments. All results reported here utilized 89 one-cm long segments, with the data being used to construct an axial profile for that particular component.

Three primary methods are available to axially distribute the available total energy deposition rates along a given element. The methods are identified here as explicit, average, and default. The explicit method utilizes the specific axial profile determined for each of the individual homogenized elements or element components. The average method utilizes an average axial profile obtained by combining the axial profiles for all elements or element components of that particular type. The default method utilizes the original non-dimensional axial profile available in NESS ${ }^{6}$.

\section{NESS Model}

The NESS model created to simulate the SNRE utilizes the nuetronics and thermal energy deposition data from a MCNP solution, and thus does not operate in a design mode, but rather an analysis mode. NESS receives mass and thermal energy deposition data for all the fuel elements, tie tubes, beryllium filler elements, control drums, beryllium barrel, stainless steel wrapper, pressure vessel, upper and lower tie tube plenums, brim shield, internal shields, and numerous hydrogen gaps from MCNP, and uses this information for both mass summations and as thermal energy sources for cycle calculations. Although NESS can estimate both pump and turbine effieicncy ${ }^{6}$, for the purposes of a baseline model, the pump and turbine efficiencies were set to $65 \%$ and $80 \%$ respectively as per SNRE documentation ${ }^{1,5}$. The various flow splits in the SNRE cycle were also modeled, with the core bypass flow being used as a binary parametric in the study. The performance of the regeneratively cooled nozzle section was manually input as a temperature and pressure drop obtained from SNRE documentation ${ }^{5,14}$.

\section{Analysis Parametrics}

The MCNP/NESS model of the SNRE is used to analyze the effects of numerous variables on engine performance, specifically overall thrust and specific impulse. These variables include fuel element and tie tube modeling detail, axial thermal energy distribution, control drum rotation, core bypass flow, and maximum allowable fuel temperature. The fuel elements and tie tubes are modeled both with explicit component breakout including all channel cladding, exterior cladding, propellant flow channels, etc., and as homogenized.

The effect of axial thermal energy deposition profiles is also evaluated by comparing MCNP element explicit profiles calculated for each individual element, MCNP determined profile averaged over all elements, and the NESS default profile applied to MCNP determined element total thermal energy deposition values. The effect of reactor control drum rotation is conducted by first establishing a baseline case at 90 degrees drum rotation. The orificing pattern required for this case to achieve maximum fuel temperature in each fuel element is then applied to MCNP data corresponding to control drum rotation angles of $0,60,80,100,110,120$, and 180 degrees. The baseline 90 degree drum rotation case is also used to determine the effect of the other analysis parameters.

\section{Model Results}

\section{A. Fuel Element and Tie Tube Model Detail}

In an effort to determine the effect of model detail on system level performance parameters, three MCNP models of the SNRE reactor core are analyzed by NESS. The complete geometry model consists of complete fuel element and tie tube geometries, which consist of all of their discrete components, as shown in Fig. 4, and propagated in the MCNP model via its lattice feature. The homogenized element geometries, however, are composed of a single component representing the average properties of the element across its cross section. One homogenized case also utilized the MCNP lattice propagation feature, while the other was constructed manually of individual elements.

These three cases are then analyzed by NESS to evaluate the impact of the models fidelity on overall system performance. The results of this analysis are shown in Table 1, and show that there is very little variation in the system level performance parameters, even though there is large difference in the amount of detail available in the models. 


\begin{tabular}{|c|c|c|c|}
\hline \multirow{2}{*}{ Parameter } & \multirow{2}{*}{\begin{tabular}{|c|} 
Complete Element \\
Geometry
\end{tabular}} & \multicolumn{2}{|c|}{ Homogenized Element Geometry } \\
\hline & & $\begin{array}{c}\text { Individual } \\
\text { Elements }\end{array}$ & $\begin{array}{c}\text { Lattice Element } \\
\text { Propagation }\end{array}$ \\
\hline Total Reactor Thermal Power (MW) & 363.011 & 363.168 & 363.240 \\
\hline Fuel Element Peak to Average Factor & 1.29 & 1.29 & 1.29 \\
\hline Number of Axial Segments & 89 & 89 & 89 \\
\hline Fuel Exit Temperature (K) & 2735.5 & 2733.3 & 2735.3 \\
\hline Engine System Isp (s) & 884.1 & 883.6 & 884.1 \\
\hline Engine Mass Flow Rate $(\mathrm{kg} / \mathrm{s})$ & 8.34 & 8.36 & 8.35 \\
\hline Thrust (kN) & 72.372 & 72.445 & 72.417 \\
\hline
\end{tabular}

Table 1. Comparison of Reactor Performance Parameters for Various Levels of MCNP Reactor Model Detail. Isp values represent Orificed SNRE engine system with peak fuel temperature of $2860 \mathrm{~K}, 3.10 \mathrm{MPa}$ chamber pressure, and no reactor bypass.

\section{B. MCNP Thermal Energy Deposition Axial Profile}

Axial thermal energy deposition profiles are evaluated for each fuel element and tie tube component to determine if there is any significant variation across the components that could affect the modeling results if homogenized element properties are used. A fuel element and tie tube from the reactor center are selected, and the results are shown in Fig. 5 and Fig. 6 respectively., and show that there are no significant differences in the normalized axial thermal energy deposition profiles for the individual components.

Next, the effect of radial location on thermal energy deposition is evaluated. Figure 7 shows the fuel matrix and $\mathrm{ZrH}$ moderator component for three fuel element and tie tube pairs. Each tie tube is adjacent to the fuel element, and each pair is located at either the center, mid radius, or outer radius of the reactor core. It is clearly seen, that there are no significant differences in the normalized axial thermal energy deposition profiles between fuel elements and tie tubes regardless of radial position. These results validate a feature of NESS, where a single normalized axial thermal energy profile can be used to represent all fuel elements, regardless of location in the reactor core.

The default thermal energy axial distribution in NESS ${ }^{6}$ is similar to that of the MCNP SNRE model data, and both are shown in Fig. 8. However, the peak of the NESS curve is shifted toward the inlet end of the reactor core. In order to determine the impact of this thermal energy deposition axial profile difference, NESS is used to analyze a MCNP data set in two modes. First, the explicit MCNP data is used directly by NESS. Next, NESS applies its default thermal energy axial distribution to the MCNP determined total thermal energy deposition for each tie tube and fuel element. A comparison of the results is shown in Table 2.

\begin{tabular}{|l|c|c|}
\hline \multicolumn{1}{|c|}{ Parameter } & $\begin{array}{c}\text { NESS Axial Thermal Energy } \\
\text { Deposition Profile }\end{array}$ & $\begin{array}{c}\text { MCNP Explicit Thermal } \\
\text { Energy Deposition Profile }\end{array}$ \\
\hline Total Reactor Thermal Power (MW) & 362.34 & 362.34 \\
\hline Number of Fuel Elements & 564 & 564 \\
\hline Number of Support Elements & 241 & 241 \\
\hline Fuel Element Peak to Average Factor & 1.027 & 1.027 \\
\hline Number of Axial Segments & 100 & 89 \\
\hline Fuel Exit Temperature (K) & 2747.5 & 2733.5 \\
\hline Engine System Isp (s) & 886.8 & 883.7 \\
\hline Engine Mass Flow Rate (kg/s) & 8.28 & 8.34 \\
\hline Thrust (kN) & 72.031 & 72.273 \\
\hline
\end{tabular}

Table 2. Summary of Engine System Parameters for NESS Default and MNCP Determined Axial Thermal Energy Deposition Profiles. Isp values represent Orificed SNRE engine system a peak fuel temperature of 2860K, $3.10 \mathrm{MPa}$ chamber pressure, and no reactor bypass. 


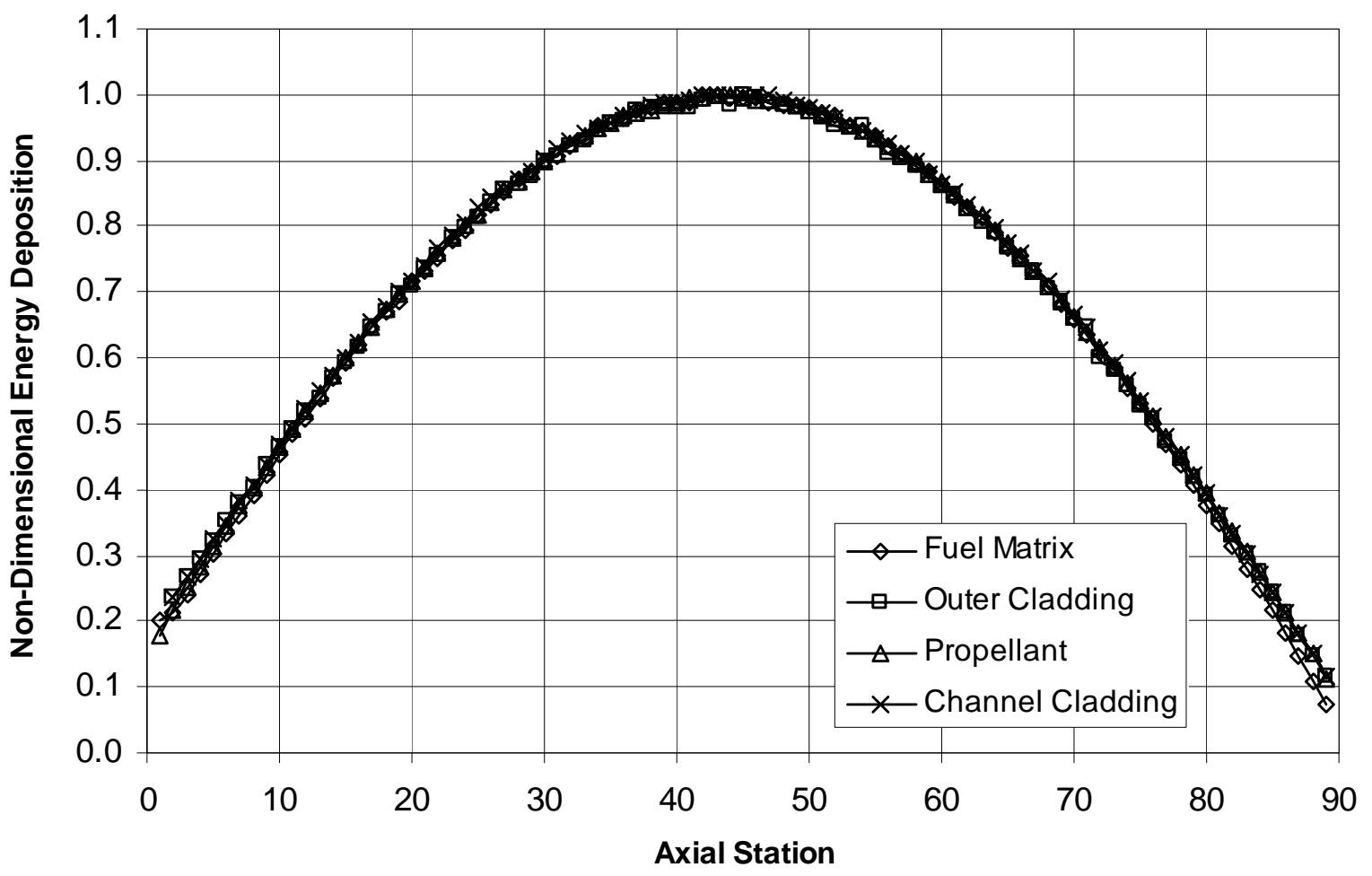

Figure 5. Thermal Energy Deposition versus Axial Station for Central Fuel Element Components. Zero indicates the propellant entrance.

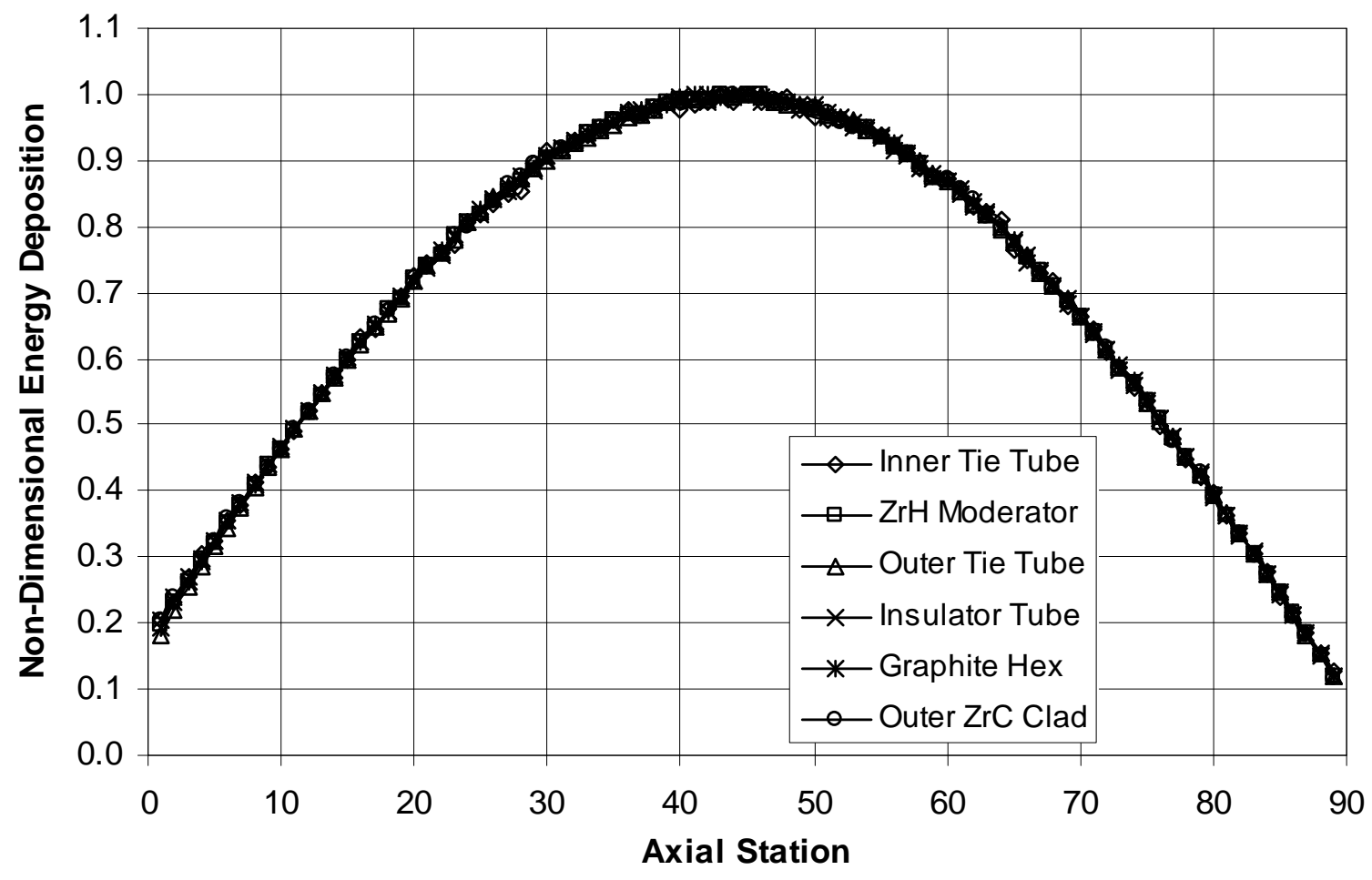

Figure 6. Thermal Energy Deposition versus Axial Station for Central Tie Tube Components. Zero indicates the propellant entrance. 


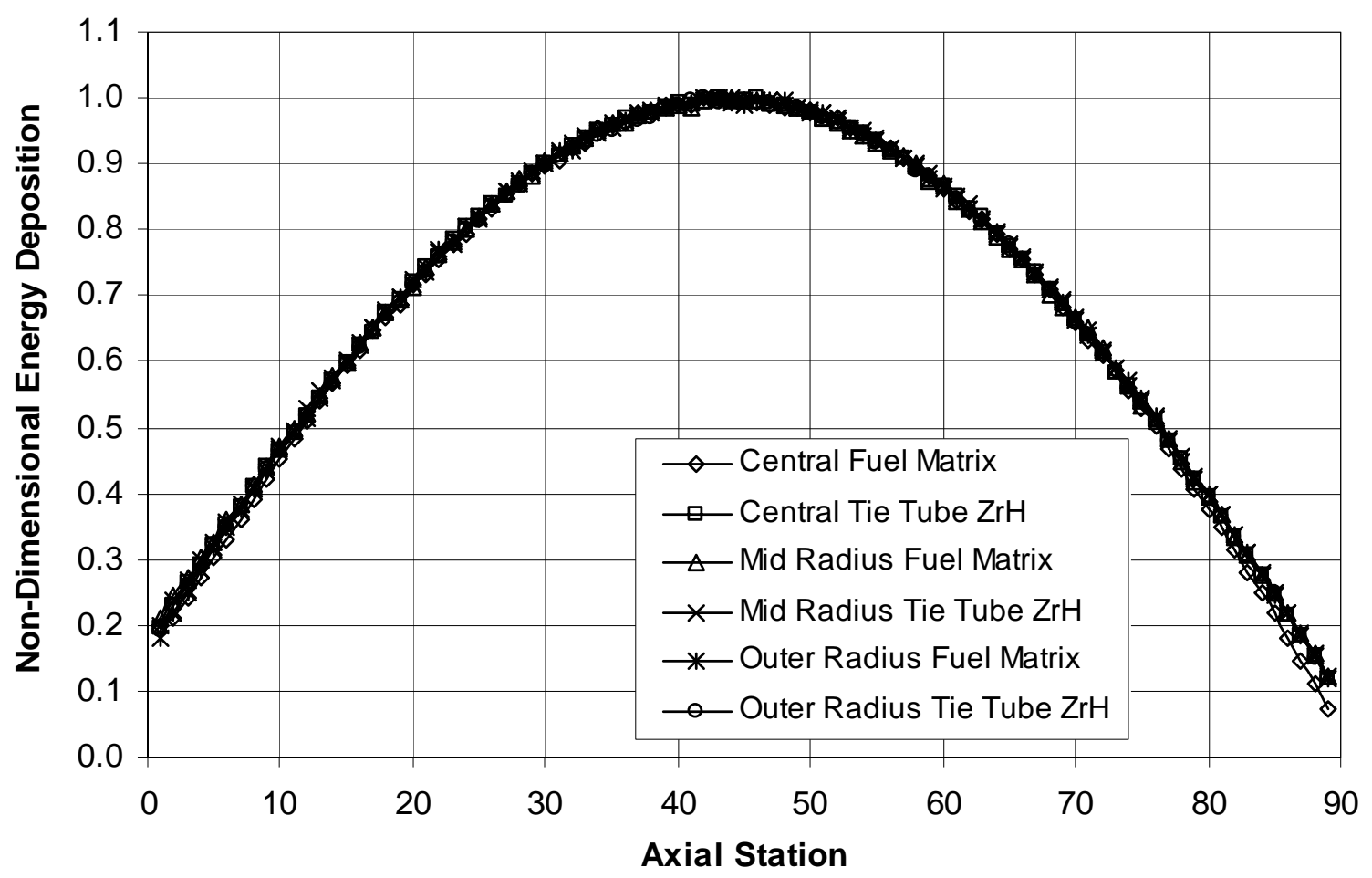

Figure 7. Thermal Energy Deposition versus Axial Station for Central, Mid Radius, and Outer Radius Fuel Element and Tie Tube Components. Tie Tube and Fuel Elements for adjacent pairs at each radial location. Zero indicates the pronellant entrance.

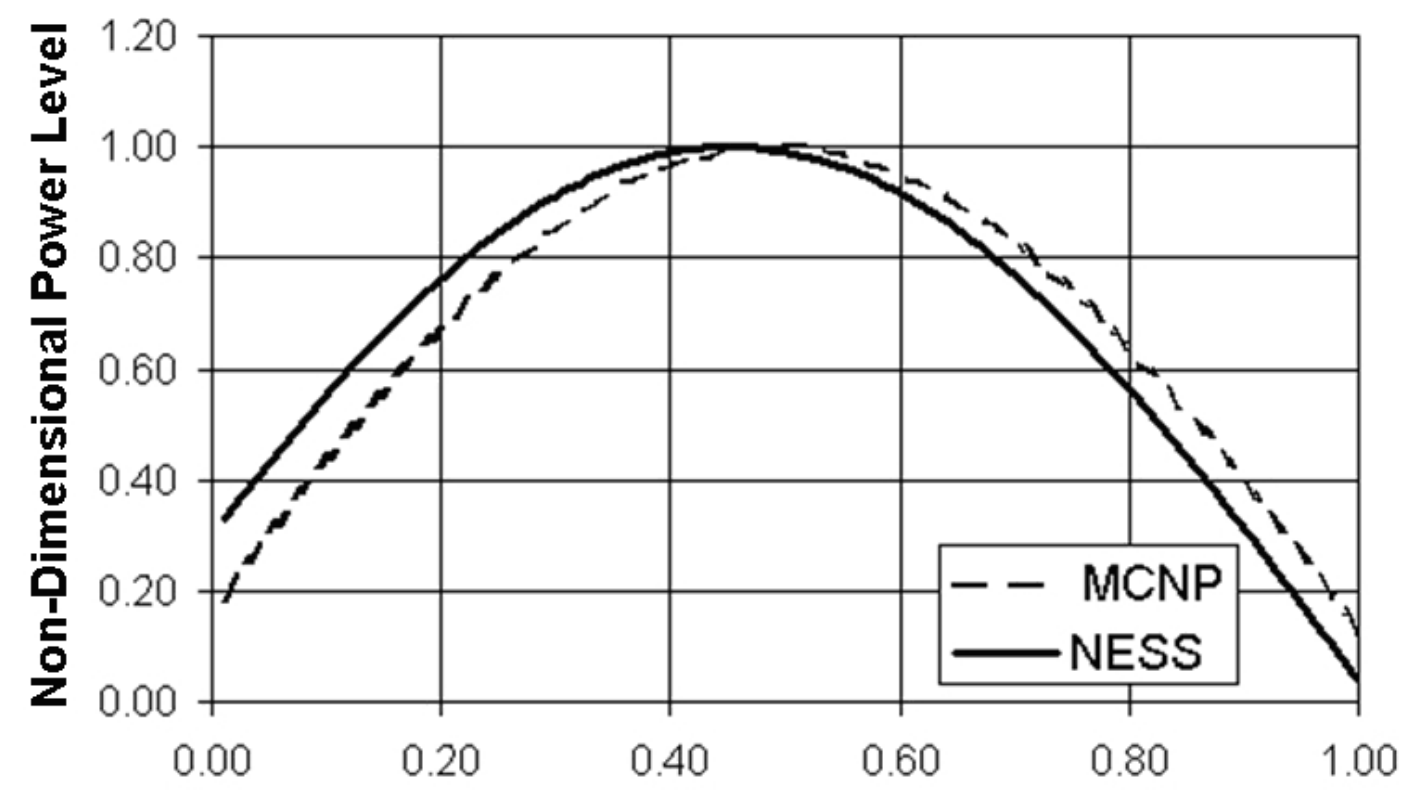

\section{Non-Dimensional Axial Location}

Figure 8. NESS and MCNP Non-Dimensional Axial Power Profile Comparison. MCNP analysis is based on uniform fissile loading of a SNRE class reactor. Zero indicates the propellant entrance, and one indicates the propellant exit. 


\section{Fuel Enrichment Zoning}

Originally, NESS conducted reactor sizing calculations using a user specified constant thermal power output for each fuel element ${ }^{6}$. This value was used in conjunction with a peak to average multiplier to simulate the peak thermal power element in the reactor core, which dictated the reactor pressure drop. NESS has since been modified to analyze each fuel element, and calculate the required orifice pressure drop to optimize the thermal performance of each fuel element, but the fuel element with the highest thermal power deposition still dictates the propellant pressure drop across the reactor core, as well as other engine parameters including TPA performance, reactor inlet feed system pressure, pressure vessel mass, and overall engine system performance. Therefore, any mature engine design will incorporate either variable enrichment zoning or variable fissile loading to flatten the reactor thermal power deposition profile.

Preliminary studies may employ uniform enrichment and fissile loadings that result in substantial energy deposition peaking. Even prior to establishing enrichment or fissile zoning, NESS can still be utilized to estimate engine system performance by calculating a suitable propellant orificing pattern to minimize fuel element temperature peaking, while maximizing propellant exit temperature.

In order to assess the effects of fuel enrichment zoning, two SNRE class reactor designs are modeled, with one utilizing uniform fissile loading and the other fuel enrichment zoning to flatten the reactor thermal power profile. Figure 9 shows a comparison of two MCNP analyzed reactor cores with the control drums at the nominal operating position of 90 degrees. This figure clearly illustrates both the effectiveness of the enrichment zoning in leveling the thermal power profile of the reactor core and in reducing the thermal energy deposition spikes at the reactor perimeter. A comparison of NESS determined reactor level parameters for the two designs is shown in Table 3. The non-orificed data highlight the differences in the performance of the two designs, with the enrichment zoned design yielding over 120s more Isp than the uniform fissile loading design. Although orficing did improve the performance of both designs, the uniform fissile loading design clearly benefited the most.

\section{Isotopic and Heating Cross Sections}

Cross section data employed in MCNP transport calculations are typically from the Evaluated Nuclear Data File $^{15,16}$ (ENDF/B) Versions V and VI. Photons produced by neutron interactions are available for transport and normally result in both local and remote energy deposition. The ENDF/B cross section evaluations for some materials of interest, in particular the hafnium isotopes, do not include explicit photon yield data. For those materials without photon yield data, the photon energy that should be available for transport is instead deposited at the site of the neutron interaction. The usual procedure is to perform the MCNP transport calculation with all ENDF/B cross section data to obtain the best possible neutronics evaluations. If detailed energy deposition solutions are needed, the MCNP transport calculation is repeated with alternate Lawrence Livermore cross section evaluations ${ }^{17}$ containing photon yield data substituted for the hafnium isotopes.

In the SNRE engine models, use of the ENDF/B cross section sets without photon yield data results in overestimating energy deposition in the hafnium absorber plates by a factor of about 2.76 ( 4.35 MW as opposed to $\sim 1.58 \mathrm{MW}$ ) and underestimating the energy absorbed in other components or lost from the reactor by an identical amount. The hafnium regions are at the core periphery and the impact of this misplaced energy deposition on NESS-calculated engine performance is of interest. An engine performance summary is shown in Table 4 for two NESS evaluations, one with all ENDF/B cross sections and one with the alternate cross section sets for hafnium. 


\begin{tabular}{|l|c|c|}
\hline \multicolumn{1}{|c|}{ Parameter } & $\begin{array}{c}\text { Uniform Fissile } \\
\text { Loading }\end{array}$ & $\begin{array}{c}\text { Enrichment } \\
\text { Zoned }\end{array}$ \\
\hline Total Reactor Thermal Power (MW) & 366.18 & 362.34 \\
\hline Number of Fuel Elements & 564 & 564 \\
\hline Number of Support Elements & 241 & 241 \\
\hline Fuel Element and Tie Tube Length (m) & 0.89 & 0.89 \\
\hline Fuel Element Peak to Average Factor & 1.298 & 1.027 \\
\hline Tie Tube Peak to Average Factor & 1.211 & 1.120 \\
\hline Peak Fuel Element Thermal Power (kW) & 784.1 & 613.4 \\
\hline Minimum Fuel Element Thermal Power $(\mathrm{kW})$ & 519.3 & 562.0 \\
\hline Average Fuel Element Thermal Power $(\mathrm{kW})$ & 604.1 & 597.5 \\
\hline Non-Orificed Pump Discharge Pressure $(\mathrm{kPa})$ & 6643.1 & 5868.5 \\
\hline Non-Orificed Engine System Isp (s) & 736.7 & 858.4 \\
\hline Non-Orificed Engine Mass Flow Rate (kg/s) & 12.185 & 8.851 \\
\hline Orificed Pump Discharge Pressure (kPa) & 6137.2 & 5839.4 \\
\hline Orificed Engine System Isp (s) & 875.0 & 875.3 \\
\hline Orificed Engine Mass Flow Rate (kg/s) & 8.597 & 8.502 \\
\hline
\end{tabular}

Table 3. Summary of Reactor Parameters for Uniform Fissile Loaded and Enrichment Zoned Reactor Designs. Isp values represent SNRE engine system, peak fuel temperature of 2860K, 3.10 MPa chamber pressure, and core reactor bypass.

\begin{tabular}{|l|c|c|}
\hline \multicolumn{1}{|c|}{ Parameter } & Isotopic Cross-Section & Heating Cross-Section \\
\hline Total Reactor Thermal Power (MW) & 366.283 & 366.178 \\
\hline Number of Fuel Elements & 564 & 564 \\
\hline Number of Support Elements & 241 & 241 \\
\hline Fuel Element and Tie Tube Length $(\mathrm{m})$ & 0.89 & 0.89 \\
\hline Fuel Element Peak to Average Factor & 1.300 & 1.298 \\
\hline Tie Tube Peak to Average Factor & 1.213 & 1.211 \\
\hline Peak Fuel Element Thermal Power $(\mathrm{kW})$ & 807.742 & 808.684 \\
\hline Minimum Fuel Element Thermal Power $(\mathrm{kW})$ & 533.777 & 535.638 \\
\hline Average Fuel Element Thermal Power $(\mathrm{kW})$ & 621.150 & 623.043 \\
\hline Pump Discharge Pressure (kPa) & 6082.4 & 6083.7 \\
\hline Engine System Isp (s) & 883.382 & 883.324 \\
\hline Engine Reactor Outlet Temperature(K) & 2732.2 & 2731.94 \\
\hline Engine Mass Flow Rate $(\mathrm{kg} / \mathrm{s})$ & 8.436 & 8.433 \\
\hline
\end{tabular}

Table 4. Summary of Reactor Parameters for Isotopic and Heating Cross-Sections. Values represent Orificed SNRE engine system with uniform fissile loading, peak fuel temperature of $2860 \mathrm{~K}, 3.10 \mathrm{MPa}$ chamber pressure, and no reactor bypass. 

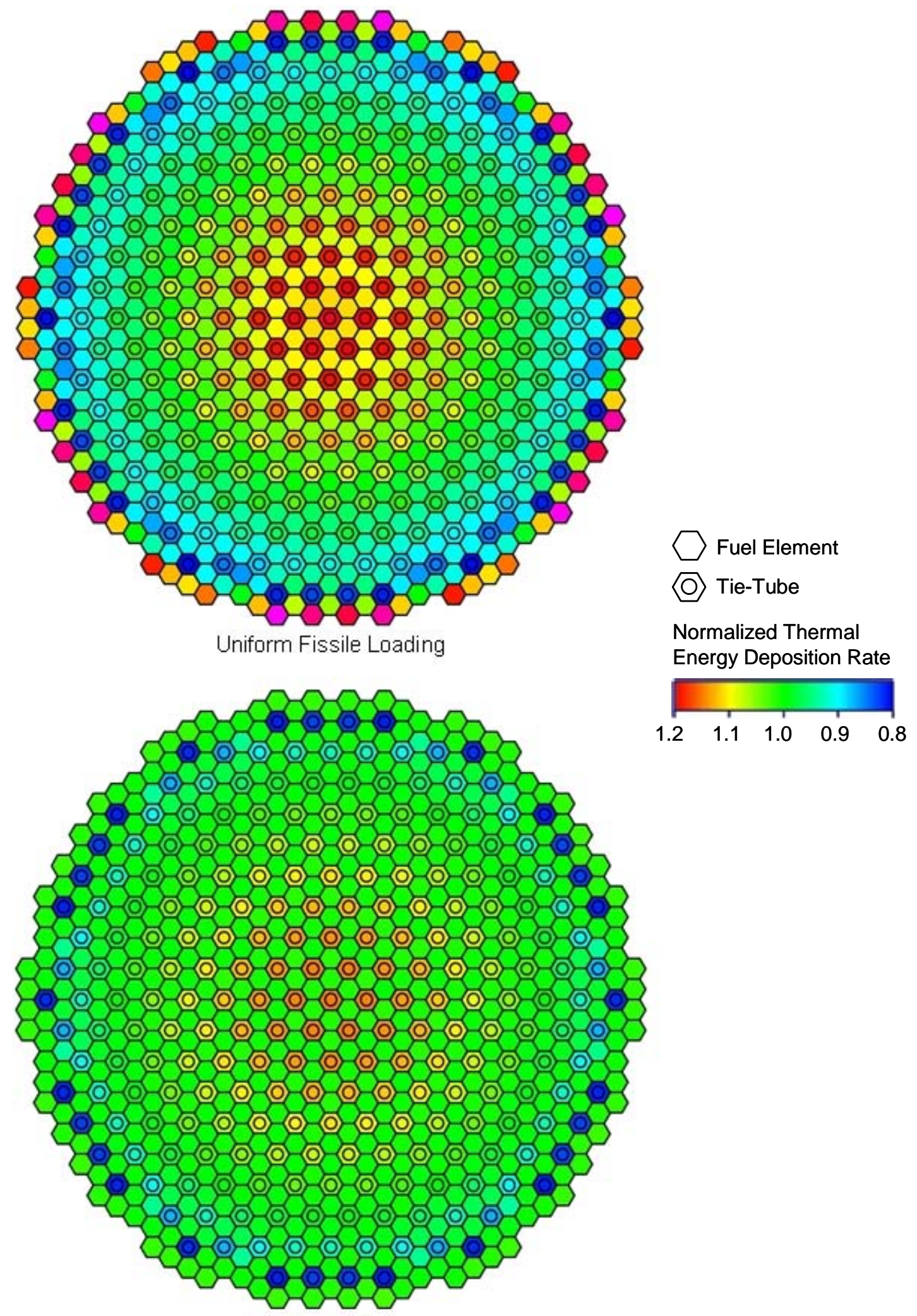

Enrichment Zoning

Figure 9. MCNP Thermal Power Profile Comparison. MCNP analysis based on uniform fissile loading (top figure) and enrichment zoning (bottom figure) of a SNRE class reactor. Profiles represent normalized total element thermal energy deposition rates at the nominal control drum setting of 90 degrees. 


\section{E. Peak Allowable Fuel Temperature}

During SNRE design, the peak allowable fuel temperature was a design variable that was traded against other system constraints. Unfortunately, the SNRE documentation does not clearly state what peak allowable fuel temperature corresponds to the documented results. In an effort to estimate this value, NESS is used with the enrichment zoned MCNP SNRE reactor model at several different maximum allowable fuel temperatures. All the NESS runs are allowed to optimize their respective orificing pattern based on peak fuel temperature. The results of this analysis, and the corresponding SNRE data, are shown in Table 5. Based on these results, a peak allowable fuel temperature of $2860 \mathrm{~K}$ is selected for future work in comparing NESS modeling work to the SNRE.

\begin{tabular}{|l|c|c|c|c|c|c|c|c|}
\hline $\begin{array}{l}\text { Peak Allowable Fuel } \\
\text { Temperature (K) }\end{array}$ & $\mathbf{2 8 5 0}$ & $\mathbf{2 8 5 5}$ & $\mathbf{2 8 6 0}$ & $\mathbf{2 8 6 5}$ & $\mathbf{2 8 7 0}$ & $\mathbf{2 8 8 0}$ & $\mathbf{2 8 9 0}$ & SNRE \\
\hline Fuel Exit Temperature (K) & 2722.4 & 2727.2 & 2733.2 & 2738.9 & 2738.9 & 2756.1 & 2767.5 & 2727.9 \\
\hline Chamber Temperature (K) & 2685.0 & 2690.1 & 2695.4 & 2700.9 & 2706.1 & 2717.4 & 2728.3 & 2696.0 \\
\hline Pump Discharge Pressure (kPa) & 5841.0 & 5845.2 & 5839.6 & 5915.8 & 5769.8 & 5812.0 & 5891.3 & 6030.0 \\
\hline Isp(s) & 873.1 & 874.2 & 875.3 & 876.5 & 877.7 & 880.1 & 882.5 & 875 \\
\hline Mass Flow Rate (kg/s) & 8.57 & 8.54 & 8.50 & 8.50 & 8.48 & 8.43 & 8.38 & 8.51 \\
\hline Thrust (kN) & 73.38 & 73.28 & 73.18 & 73.06 & 72.95 & 72.73 & 72.51 & 72.99 \\
\hline
\end{tabular}

Table 5. Effect of Peak Allowable Fuel Temperature on Reactor Performance Parameters. Values represent Enrichment Zoned SNRE engine system model with core bypass and 3.10 MPa chamber pressure. Shaded region indicates selected peak fuel temperature for SNRE and MCNP/NESS model comparison.

\section{F. SNRE and NESS/MCNP State Point Comparison}

Using the results from the previous analysis, a combined NESS and MCNP model of the SNRE is evaluated using zoned enrichment with a peak allowable fuel temperature of $2860 \mathrm{~K}$. A single MCNP determined normalized axial thermal energy deposition profile is used with discrete total element thermal energy deposition values for all the fuel elements and tie tubes. The thermodynamic state point results from this model are compared to the SNRE values in Table 6.

\begin{tabular}{|l|c|c|c|c|c|c|}
\hline \multirow{2}{*}{ Location } & \multicolumn{2}{|c|}{ Temperature (K) } & \multicolumn{2}{c|}{ Pressure (kPa) } & \multicolumn{2}{c|}{ Mass Flow Rate (kg/s) } \\
\cline { 2 - 7 } & SNRE & NESS & SNRE & NESS & SNRE & NESS \\
\hline Pump Inlet & 17.00 & 17.00 & 0.124 & 0.194 & 8.51 & 8.50 \\
\hline Pump Exit & 19.80 & 17.00 & 6.03 & 5.839 & 8.51 & 8.50 \\
\hline Tie Tube Inlet & 20.30 & 23.61 & 5.72 & 5.632 & 4.05 & 4.05 \\
\hline Tie Tube Exit & 428.90 & 444.74 & 5.02 & 4.942 & 4.05 & 4.05 \\
\hline Slat Inlet & 20.30 & 23.61 & 5.72 & 5.632 & 0.64 & 0.64 \\
\hline Slat Exit & 431.50 & 510.67 & 4.86 & 3.969 & 0.64 & 0.64 \\
\hline Turbine Inlet & 428.60 & 444.74 & 5.02 & 4.943 & 4.13 & 4.05 \\
\hline Turbine Outlet & 415.60 & 420.73 & 4.13 & 4.145 & 4.69 & 4.05 \\
\hline Nozzle Regen Inlet & 21.40 & 23.61 & 4.63 & 5.632 & 3.83 & 3.82 \\
\hline Nozzle Regen Outlet & 240.40 & 242.61 & 4.22 & 4.317 & 3.83 & 3.82 \\
\hline Reflector Outlet & 294.90 & 362.52 & 4.22 & 4.145 & 3.83 & 3.82 \\
\hline Core Inlet & 370.10 & 407.25 & 3.96 & 3.627 & 8.51 & 8.50 \\
\hline Fuel Element Exit & 2728.00 & 2733.23 & 3.10 & 3.103 & 8.33 & 8.32 \\
\hline Core Bypass Exit & 370.10 & 402.53 & 3.10 & 3.103 & 0.18 & 0.19 \\
\hline Thrust Chamber & 2695.80 & 2695.42 & 3.10 & 3.103 & 8.51 & 8.50 \\
\hline Thrust Chamber w/ Regen & 2628.80 & 2625.36 & 3.10 & 3.103 & 8.51 & 8.50 \\
\hline
\end{tabular}

Table 6. Flow Circuit State Point Comparison of SNRE Data and NESS Model Results Incorporating MCNP Zoned Enrichment Model Data. NESS values represent orificed engine system with core bypass and peak fuel temperature of $2860 \mathrm{~K}$. 


\section{G. Control Drum Rotation}

The effect of control drum rotation on the NESS and MCNP SNRE model is analyzed by assuming that the orficing pattern is optimized for the nominal operating baseline case (peak fuel temperature of $2860 \mathrm{~K}$ and 90 degree control drum position). This fixed orificing pattern is used by NESS in conjunction with MCNP data for control drum rotations of $0,60,80,100,110,120$, and 180 degrees. Since the peak allowable fuel temperature remains 2860 $\mathrm{K}$, it is expected that the TPA will have to deliver both a higher propellant mass flow rate and pump discharge pressure in order to provide adequate fuel element cooling with the non-optimal orificing pattern. This will, however, reduce the average propellant core exit temperature and reduce delivered Isp.

A control drum position of 90 degrees is considered the nominal operating point, with 80 and 100 degrees bounding the typical operational range of the engine. The 60, 110, and 120 degree control drum positions are analyzed to illustrate the degradation of engine performance due to the change in spatial total thermal energy deposition rate profile at far off design conditions. The 0 and 180 degree conditions, however, represent an absolute worst case scenario and represent the control drums being rotated to their limits. The enrichment zoned case presented in Fig. 9 represents the total thermal energy deposition rate for the SNRE reactor model operating at the nominal 90 degree control drum position. When compared with the corresponding data for the 80 and 100 degree control drum positions shown in Fig. 10, one notices that there is very little difference in the total thermal energy deposition profiles, thus indicating small changes in the reactor core total thermal energy deposition profiles during its normal operational envelope, but Isp is reduced by more than $20 \mathrm{~s}$ when which is very significant. Figure 11 shows the total thermal energy deposition profiles for the extreme drum positions of 0 and 180 degrees, and clearly shows that the fuel elements around the core periphery are the ones most affected by the extreme drum positions. A summary of various engine system level parameters at the various control drum positions is given in Table 7.

\begin{tabular}{|l|c|c|c|c|c|c|c|c|}
\hline Drum Rotation & $\mathbf{0}^{\mathbf{0}}$ & $\mathbf{6 0}^{\mathbf{0}}$ & $\mathbf{8 0}^{\mathbf{0}}$ & $\mathbf{9 0}^{\mathbf{0}}$ & $\mathbf{1 0 0}^{\mathbf{0}}$ & $\mathbf{1 1 0}^{\mathbf{0}}$ & $\mathbf{1 2 0}^{\mathbf{0}}$ & $\mathbf{1 8 0}^{\mathbf{0}}$ \\
\hline $\begin{array}{l}\text { Total Reactor Thermal } \\
\text { Power (MW) }\end{array}$ & 350.2 & 356.4 & 360.3 & 362.3 & 364.3 & 366.2 & 368.0 & 373.2 \\
\hline $\begin{array}{l}\text { Fuel Element Peak to } \\
\text { Average Factor }\end{array}$ & 1.083 & 1.050 & 1.028 & 1.027 & 1.059 & 1.094 & 1.120 & 1.220 \\
\hline $\begin{array}{l}\text { Tie Tube Peak to Average } \\
\text { Factor }\end{array}$ & 1.185 & 1.168 & 1.158 & 1.150 & 1.148 & 1.142 & 1.136 & 1.123 \\
\hline $\begin{array}{l}\text { Peak Fuel Element } \\
\text { Thermal Power (kW) }\end{array}$ & 643.72 & 635.53 & 629.48 & 632.65 & 656.34 & 681.66 & 702.90 & 776.87 \\
\hline $\begin{array}{l}\text { Minimum Fuel Element } \\
\text { Thermal Power (kW) }\end{array}$ & 479.12 & 555.50 & 573.70 & 579.69 & 585.02 & 589.89 & 594.75 & 604.85 \\
\hline $\begin{array}{l}\text { Average Fuel Element } \\
\text { Thermal Power (kW) }\end{array}$ & 594.5 & 605.5 & 612.6 & 616.3 & 619.9 & 623.3 & 626.6 & 636.3 \\
\hline $\begin{array}{l}\text { Pump Discharge Pressure } \\
\text { (kPa) }\end{array}$ & 6488.7 & 6268.0 & 6132.9 & 856.1 & 6221.1 & 6631.4 & 7041.6 & 8863.2 \\
\hline Engine System Isp (s) & 828.3 & 848.9 & 862.5 & 883.7 & 861.1 & 837.9 & 818.1 & 757.7 \\
\hline $\begin{array}{l}\text { Engine Mass Flow Rate } \\
\text { (kg/s) }\end{array}$ & 9.21 & 8.91 & 8.72 & 8.34 & 8.84 & 9.40 & 9.92 & 11.74 \\
\hline
\end{tabular}

Table 7. Summary of Engine Parameters for Numerous Control Drum Positions. NESS values represent an orificed and enrichment zoned SNRE engine system with no core bypass and a peak fuel temperature of $2860 \mathrm{~K}$. Shaded region indicates nominal operating range.

\section{H. Engine System Masses}

Although NESS can estimate various NTR engine subsystem masses, it can also receive component mass data from MCNP $^{12}$. For this analysis, the MCNP mass results are used in conjunction with the NESS mass estimation relationships, with NESS providing mass data for necessary engine subsystems only if it is not provided by MCNP. When comparing the results to those found in the SNRE documentation it was discovered that there are discrepancies regarding the beryllium masses. The beryllium barrel, reflector, filler elements, and control drums were modeled in MCNP as per SNRE specifications, and the MCNP calculated component masses used are in the subsequent analysis. 

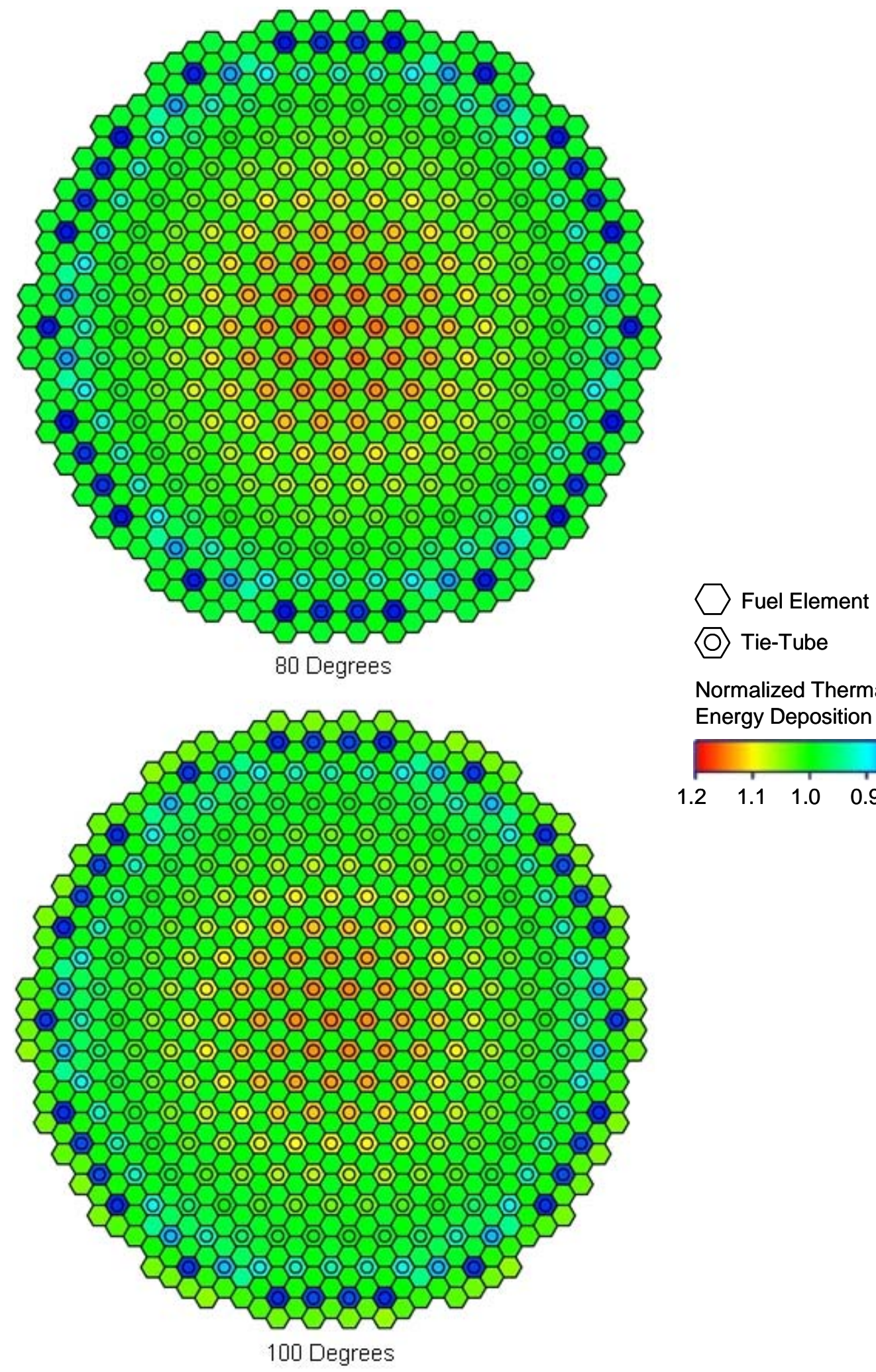

Normalized Thermal Energy Deposition Rate

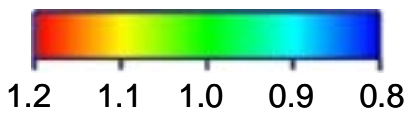

Figure 10. Reactor Thermal Energy Deposition Profiles for Control Drum Positions of 80 and 100 Degrees. Profiles represent normalized total element thermal energy deposition rates. 


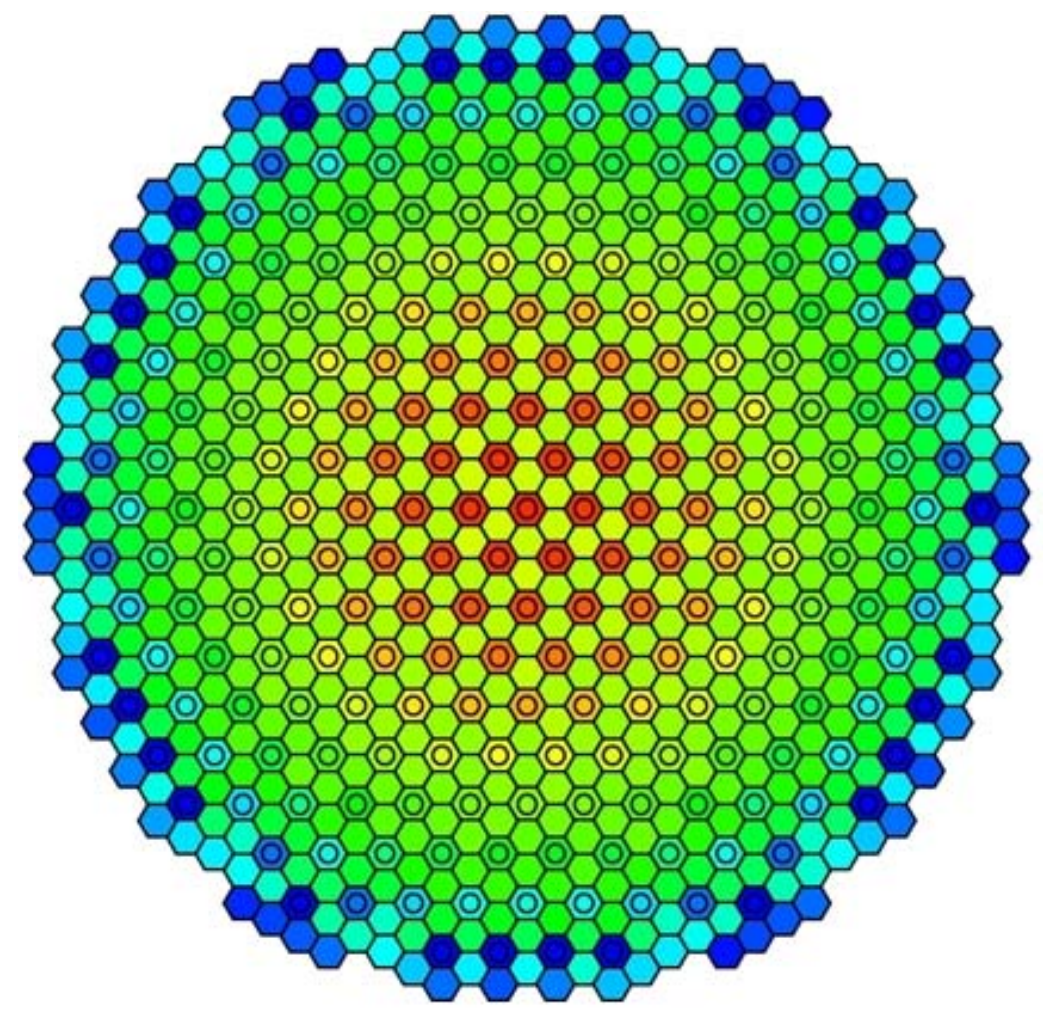

$\square$ Fuel Element
(0) Tie-Tube

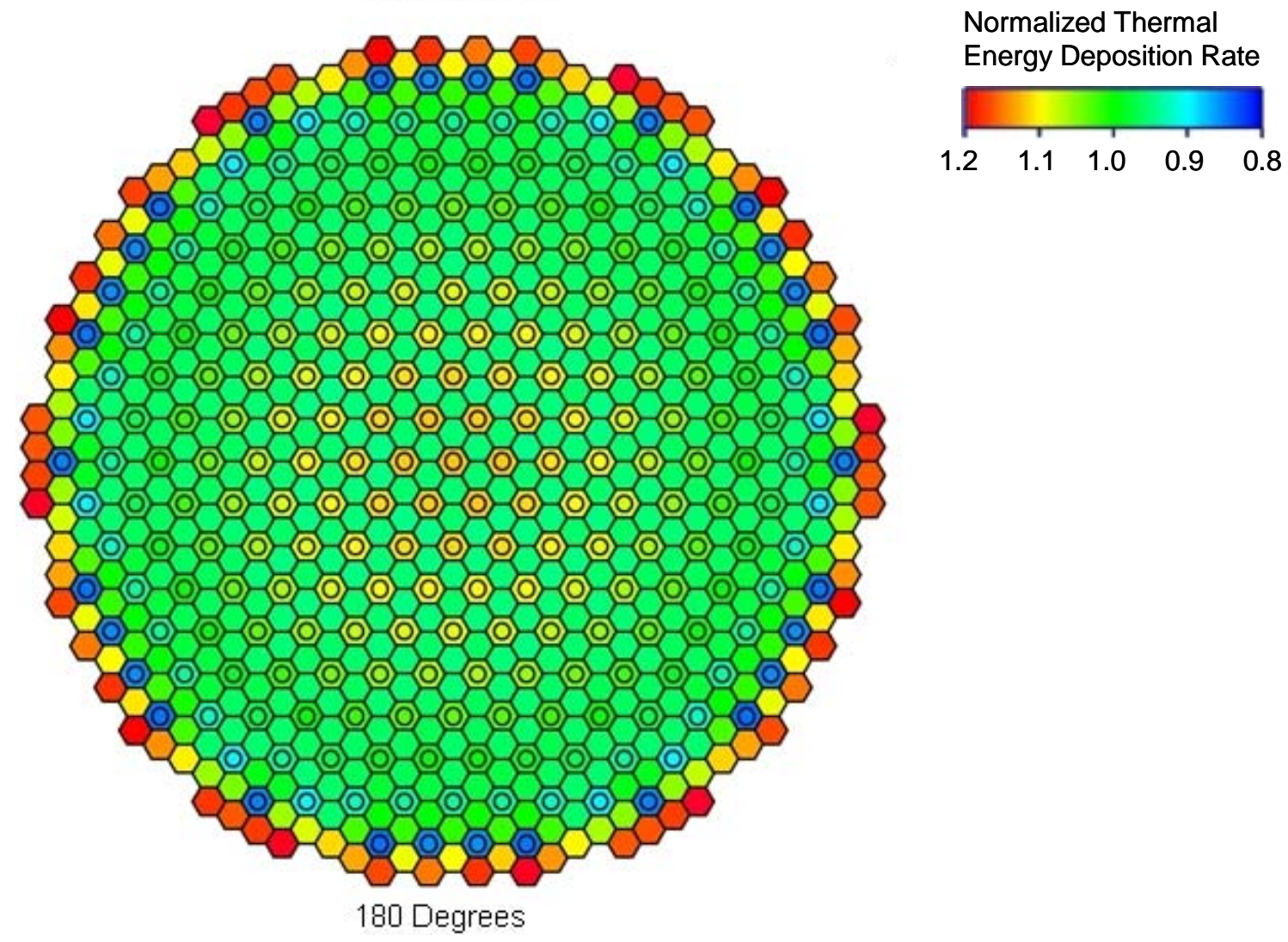

Normalized Thermal Energy Deposition Rate

Figure 11. Reactor Thermal Energy Deposition Profiles for Control Drum Positions of 0 and 180 Degrees. Profiles represent normalized total element thermal energy deposition rates. 
A comparison of the engine sub system masses is shown in Table 8. The combination of NESS and MCNP results in a good match with SNRE mass data for the fuel elements, tie-tubes, and most other engine subcomponents. The nozzle masses differ due to both material and design differences. SNRE documentation states that the nozzle skirt material was still under consideration, thus the exact material used for the mass quoted in the text is in question, whereas NESS assumes carbon fiber. The SNRE nozzle was also designed to fold via an actuator. The NESS/MCNP model does not model this feature, or the corresponding hardware required to implement it, thus the discrepancy in the valve and actuator mass. Electronics mass is a very difficult comparison, due to both the radical changes in electronics over the years and the current lack of instrumentation requirements for a NTR system. For the sake of this comparison, the SNRE value is used for both in this analysis.

The beryllium filler element mass is not explicitly stated in the documentation, but is implicitly rolled up in the quoted reactor core and hardware mass value. The value shown in Table 8 is thus calculated from other SNRE data. Although the SNRE documentation mentions the use of a metallic core wrapper, no mass value was associated with this item, thus it is left blank in Table 8.

\begin{tabular}{|l|c|c|}
\hline \multicolumn{1}{|c|}{ Component } & SNRE & MCNP/NESS \\
\hline Fuel Elements and Hardware (kg) & 522.8 & 527.5 \\
\hline Tie-Tubes and Hardware (kg) & 246.7 & 250.0 \\
\hline Beryllium Barrel (kg) & 13.3 & 84.6 \\
\hline Reflector Assembly (kg) & 555.5 & 605.5 \\
\hline Beryllium Filler Blocks (kg) & 35.37 & 30.9 \\
\hline Stainless Steel Wrapper (kg) & - & 42.7 \\
\hline Internal Shield (kg) & 239.5 & 249.5 \\
\hline Turbopump Assembly (kg) & 40.8 & 48.9 \\
\hline Support Plate (kg) & 36.6 & 36.98 \\
\hline Hot End Hardware (kg) & 26.7 & 28.28 \\
\hline Pressure Vessel (kg) & 150.1 & 148.9 \\
\hline Nozzle (kg) & 224.5 & 150.2 \\
\hline External Gimbal (kg) & 27.7 & 25.8 \\
\hline Lines (kg) & 15.4 & 12.3 \\
\hline Valves and Actuators (kg) & 206.8 & 37.00 \\
\hline Electronics (kg) & 158.8 & 158.8 \\
\hline Contingency (2\%) & 50.0 & 48.8 \\
\hline Total (kg) & 2550 & 2487 \\
\hline
\end{tabular}

Table 8. Comparison of NTR Engine System Masses. MCNP/NESS values represent an orificed and enrichment zoned engine system with core bypass and a peak fuel temperature of $2860 K$.

\section{Conclusion}

The combined use of MCNP and NESS yields a computational model that closely simulates the predicted thermodynamic state points and overall system performance of the SNRE, as well as its estimated mass. This model can be used to asses the effects of element modeling detail, enrichment zoning, axial total thermal energy deposition rate distribution, peak allowable fuel temperature, and control drum rotation on an SNRE class system. It is also used to show that enrichment zoning creates a very continuous total thermal energy deposition rate profile through the expected operational range of a NTR system.

\section{Acknowledgments}

This work was performed using FY2007 funding provided by Prometheus Power and Propulsion at NASA HQ, and by the Department of Energy's Idaho National Laboratory. 


\section{References}

1. Fittje, J. E. and Buehrle, R. J., "Conceptual Engine System Design for NERVA derived 66.7KN and 111.2KN Thrust Nuclear Thermal Rockets,” Space Technology and Applications International Forum [CD-ROM], Vol. 813, AIP, Melville, NY, 2006.

2. Koenig, D. R., "Experience Gained from the Space Nuclear Rocket Program (Rover)," Los Alamos National Lab., Report LA-10062-H, Los Alamos, NM, May 1986.

3. Schnitzler, B., and Borowski, S., "Nuetronics Models and Analysis of the Small Nuclear Rocket Engine (SNRE)," AIAA2007-5618, July 2007.

4. Stewart, Mark E. and Schnitzler, Bruce G., "Thermal Hydraulics and Structural Analysis of the Small Nuclear Rocket Engine (SNRE) Core,” AIAA-2007-5619, July 2007.

5. Durham, F. P., "Nuclear Engine Definition Study Preliminary Report, Volume 1 - Engine Description,” Los Alamos National Laboratory, Report LA-5044-MS Vol 1, Los Alamos, NM, Sept. 1972.

6. Pelaccio, Schiel, and Petrosky, “Nuclear Engine System Simulation (NESS): Version 2.0,” NASA CR-191081, 1993.

7. Borowski, S., McGuire, M., and Beke, "Nuclear Thermal Rocket/Vehicle Design Options for Future NASA Missions to the Moon and Mars,” NASA TM-1993-107071, 1993.

8. Watson, C.W., "Nuclear Rockets: High-Performance Propulsion for Mars,” Los Alamos National Laboratory Report LA12784-MS, May, 1994.

9. Taub, J. M., "A Review of Fuel Element Development for Nuclear Rocket Engines," Los Alamos National Lab., Rept. LA5931, Los Alamos, NM, June 1975.

${ }^{10 .}$ Lyon, L. L., "Performance of (U,Zr)C-Graphite (Composite) and of (U,Zr)C (Carbide) Fuel Elements in the Nuclear Furnace 1 Test Reactor," Los Alamos National Lab., Rept. LA-5398-MS, Los Alamos, NM, Sept 1973.

11. Fowler, J.R., “GASPLUS User's Manual,” NASP Contractor Report 1012, March, 1988.

12. Fittje, Jame E., "Upgrades to the Nuclear Engine System Simulation (NESS) Code,” AIAA-2007-5620, July 2007

13. X-5 Monte Carlo Team, “MCNP - A General Monte Carlo N-Particle Transport Code, Version 5,” Los Alamos National Laboratory, Report LA-UR-03-1987, Los Alamos, NM, April 2003.

14. Durham. F. P., "Nuclear Engine Definition Study Preliminary Report, Volume 2- Supporting Studies," Los Alamos National Lab., Rept. LA-5044-MS Vol 2, Los Alamos, NM, Sept 1972.

15. Garber, D., (Editor), “Evaluated Nuclear Data File (ENDF/B-V)”, National Nuclear Data Center, Brookhaven National Laboratory Report BNL-17541, October 1975.

16. McLane, V., Dunford, C. L., and Rose,P. F., (Editors), "ENDF-102, Data Formats and Procedures for the Evaluated Nuclear Data File ENDF-6 (Revised)”, Brookhaven National Laboratory Report BNL-NCS-44945, November 1995.

${ }^{17 .}$ Howerton, R. J., et al., "The LLL Evaluated Nuclear Data Library (ENDL): Evaluation Techniques, Reaction Index, and Descriptions of Individual Reactions”, Lawrence Livermore National Laboratory Report UCRL-50400, Volume 15, Part A, September 1975. 